\title{
Method of thermal detection of leakages in construction of deep excavation: A real case study in Poland
}

\author{
Krzysztof Radzicki ${ }^{1, *}$, Lukasz Rybiański ${ }^{2}$ and Pawet Popielski ${ }^{3}$ \\ ${ }^{1}$ Cracow University of Technology, Faculty of Environment Engineering, ul. Warszawska 24, \\ 31-155 Cracow, Polska \\ ${ }^{2}$ NeoStrain Company, ul. Lipowa 3, 30-702 Cracow, Polska \\ ${ }^{3}$ Warsaw University of Technology, Faculty of Building Services, Hydro and Environmental \\ Engineering, ul. Nowowiejska 20, 00-653 Warsaw, Polska
}

\begin{abstract}
The thermal method is nowadays the only one that allows precise location of leaks in a shorings of a planned deep excavation, still before this excavation is made. It also allows to determine the leak intensity. As a consequence, it enables precise and early repair work, especially sealing. It allows to prevent or significantly reduce the serious consequences and losses resulting from a leaky excavation shoring. The paper presents the first in Poland case of the thermal detection of leaks in the excavation shoring at a construction site. This method has proven very effective in solving this complicated problem. The leaks were many and occurred in the diaphragm wall as well as under its lower edge. The depth of their occurrence reached over forty meters. The substrate's geology was highly heterogeneous. The method produced accurate details about the locations and intensity of the leaks.
\end{abstract}

\section{Introduction}

Numerous structures, especially buildings, are erected with deeply founded underground parts, particularly in intensely urbanised agglomeration-like areas. These underground parts foundations and structural elements are set in deep excavations very often below the groundwater level. Such deep excavations are typically protected with shoring. Shoring shall ensure the stability of excavation and shall protect against the groundwater inflow. Shoring technologies are many, but none reliably warrants tightness. Besides the errors of geological recognition, design, and workmanship, no shoring tightness is ever certain, especially in difficult ground conditions and for deep installations. Shorings often leak in the executive practice. If the excavation shoring and/or the impermeable soil layer as an element of the sealed zone around the excavation is leaky, then during the earth works groundwater can rapidly inflow into the excavation. Moreover, the leak can wash out soil from surrounding of the excavation into it by erosion process, particularly in the case of very dynamic piping erosion. These processes pose a significant threat to the safety of the excavation, as well as

${ }^{*}$ Corresponding author: radzicki@hotmail.fr 
to the neighbouring buildings and underground infrastructure. Their occurrence can significantly increase the project cost, and significantly delay or even prevent the construction works [1-4].

The only method currently available for early and precise leak detection in the shoring of planned excavation made with diaphragm walls, sheet pile walls, or DSM walls, before this deep excavation execution is the thermal method. It also detects zones of intense water flow in the ground, inside the future excavation's contour and in its surroundings alike. The method enables early and precise determination of the leakage locations and the destructive process development dynamics, which is crucial for minimizing the failure risk and/or scope. This allows for early, effective, and optimal preventive and/or repair actions while minimizing their costs [4]. The thermal method is based on coupled heat and water transport. Even a soil moisture change alone significantly affects the heat transport rate in the ground in the heat conduction process. A water flow occurrence, including a leak, generates an intense, advective heat transport in the ground, proportional to the flow rate. In turn, the water flow in the soil is affected by erosive processes, which in a characteristic way affect the field of in-ground temperature. As a consequence, the thermal method allows the detection and analysis of seepage processes, including leaks and of erosion processes [4, 5].

This method was first developed to detect leaks and examine erosive processes in earth dams and flood embankments. In this respect, the thermal method has a large variety of different temperature sensors and data analysis methods. Their selection depends on the considered issue and a number of criteria, as to the scope and objectives, and the type of the object concerned, and the problems analysed [5]. One of the types of sensors used are linear thermal sensors, which were also adapted to monitoring the excavation shoring tightness. They enable the water flow examination by passive and active methods alike [4].

The thermal method in the aspect of its application for deep excavations is briefly described in the second chapter. A detailed description of the thermal method's origins, development and current status, including the leak detection in deep excavations, is presented in [4]. It also presents the leakage and erosion processes development scenarios and patterns for deep excavations and discusses the relations between heat transport and the filtration and erosion processes.

In Poland, the technology of the thermal method's application to excavation shoring tightness investigation was developed by NeoStrain company and the Cracow University of Technology. The technology's first R\&D applications were implemented in Warsaw in 2016 in cooperation with the Warsaw University of Technology. This implementation included selected fragments of excavation shoring. These were the first excavation shoring tightness investigation by the thermal method in Poland [4]. In the following years, the method had proved its effectiveness, allowing, inter alia, a quick and accurate diagnosis of a complicated shoring leak case on a one construction site in Poland. Presentation of this case is the main goal of this article.

\section{Deep excavation shoring investigations by the thermal method}

Excavation shoring tightness is investigated by the thermal method after the planned excavation shoring has been constructed but before digging and removing soil. For this purpose, linear thermal sensors are installed vertically inside the future excavation area (Figure 1). In order to monitor the excavation shoring walls' tightness, the sensors are mounted along them. Monitoring of the structure's bottom part tightness requires the installation of an additional network of sensors. Resolution of the method depends on distance between the sensors. After first detection of zone of the leakage, additional thermal sensors can be installed in this zone. In this case a spatial resolution of the method can equals to $1 \mathrm{~m}$. Water inside the soil in the zone of planned excavation is pumped out to lower its 
level. In consequence this level is below the groundwater level outside the structure. This makes a pressure and a water inflow through gaps (leaks) in the walls and/or floor. This leak affects the temperature of installed sensors, the more the larger the water inflow rate is.

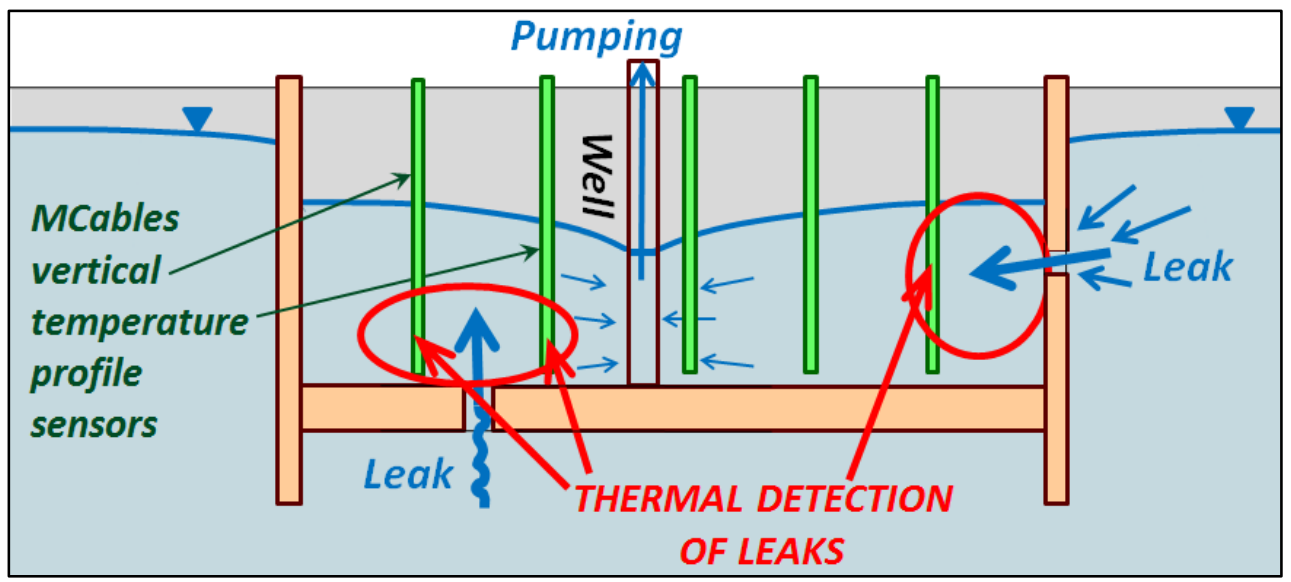

Fig. 1. Schema of leaks detection using the thermal method.

There are two thermal leak detection methods, passive and active. The passive method measures the soil own temperatures. The sealed and load-bearing elements of a deep excavation shoring (e.g. diaphragm walls) are often made of cement-based materials. Due to cement hydration a heat is released, which increases the substrate temperature in the surrounding soil. The leaking water disturbs this thermal field. The hydration heat, depending on the case, can be used to detect leaks up to several weeks after the shoring completion. The active method is used when the hydration has ceased, and the resulting heat is dissipated, or the excavation shoring has been made of a non-heat-emitting material (e.g. sheet piles). In this case, temperature sensors integrated with the heaters are mounted in the ground. Analysis of dissipation characteristics of the heat generated by the heaters allows the detection of leaks and evaluation of their severity [4].

\section{The first case of detection of leak in excavation shoring by thermal method in Poland}

\subsection{Introduction and object description}

This chapter presents the problem of leakage and erosion processes and their investigation which took place during 2018 during excavation for the underground part of a multi-storey building. The building is located in one of major Polish cities.

The geological investigations were carried out firstly in five locations of the object site in its corners and central part. Figure 2A shows the designed geological cross-section diagonally. The underground part of the building was designed as a four-level underground garage with the cross-section shown in Figure 3. 


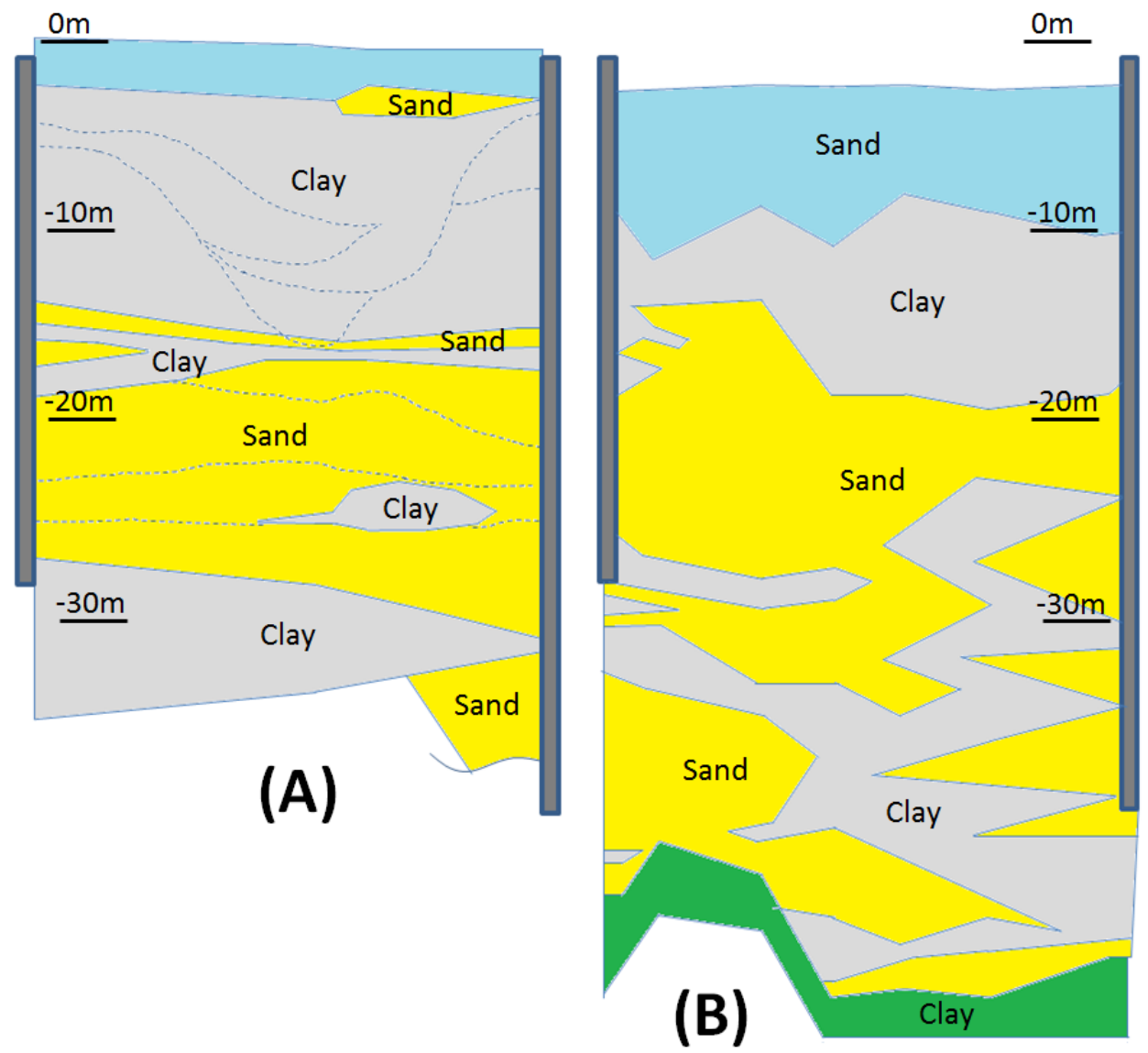

Fig. 2. Selected geological cross-sections diagonally with diaphragm walls (gray rectangles) location marked; (A) design geological cross-section, (B) cross-section based on repeated geological surveys.

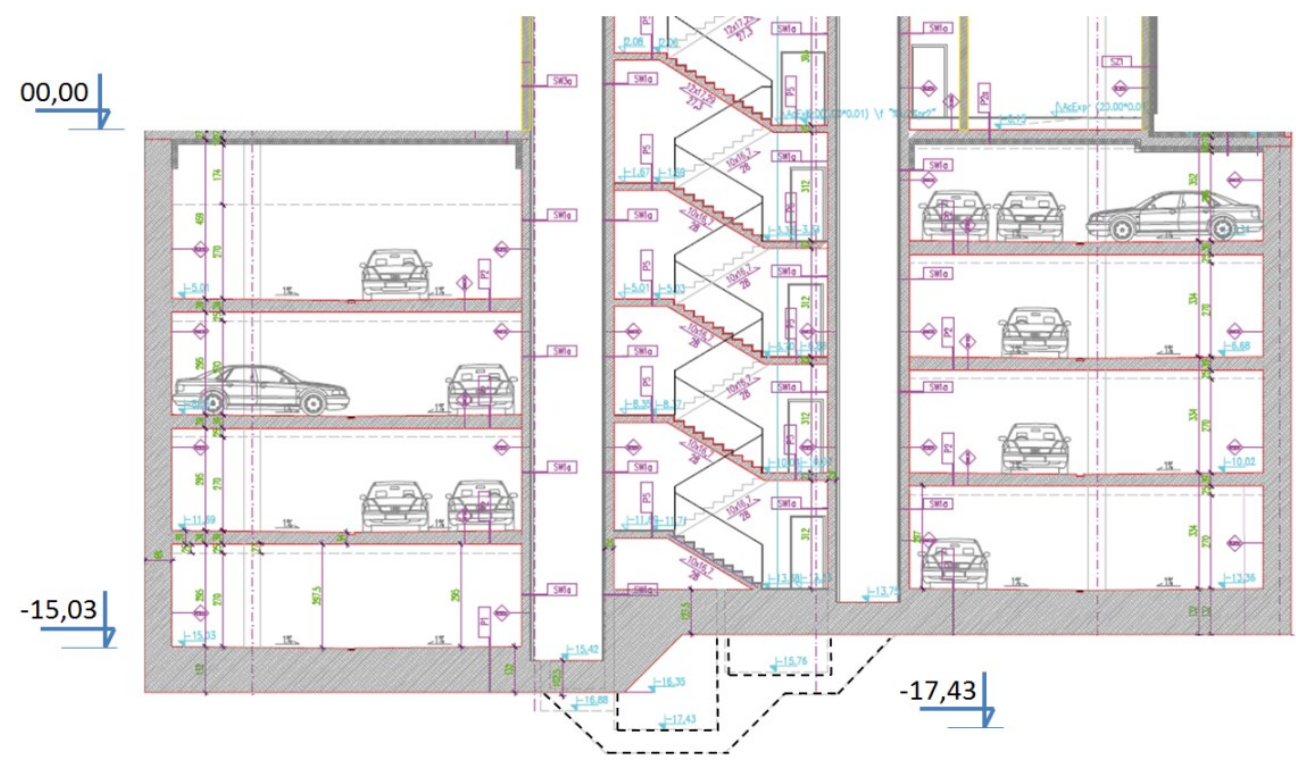

Fig. 3. Cross section by underground garage of the planned building. 


\subsection{Problem description}

First, the diaphragm walls were built off the terrain surface. They were designed as the future excavation shoring, and ultimately the garage walls. The tight layer under the excavation bottom was planned to be provided by the horizontal layer of cohesive soils. According to the design, the diaphragm walls were anchored in, or passed through, it. Then, the excavation was started successively, along with the installation of struts in its corners (Figure 4). During the earthworks, ground water was pumped out to lover its level under the excavation. After reaching the excavation depth of $9 \mathrm{~m}$ below the diaphragm wall head edge, a soil elevation related water inflow appeared in the excavation's central and lowest part. It was successfully contained in a steel pipe. After a few days, another water inflow appeared in one of the excavation corners. It was also contained in a steel pipe. However, in the next few days, other water inflows appeared around it. They were intense and numerous enough that the decision was made to backfill the excavation, which was done. The construction works were stopped.

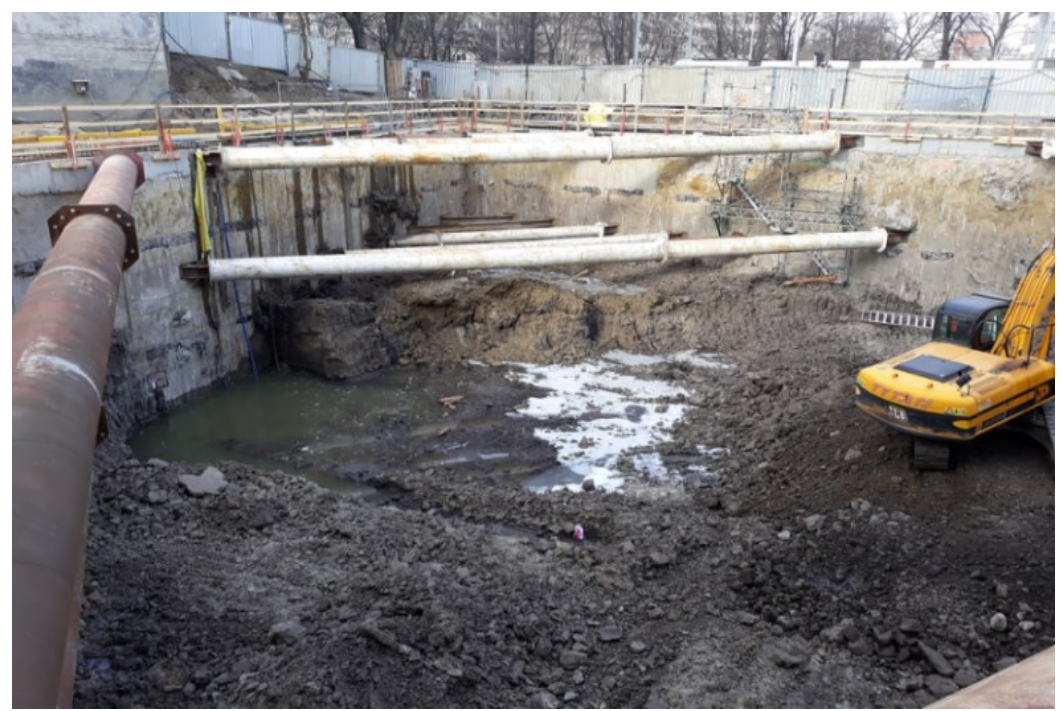

Fig. 4. Excavation works in progress.

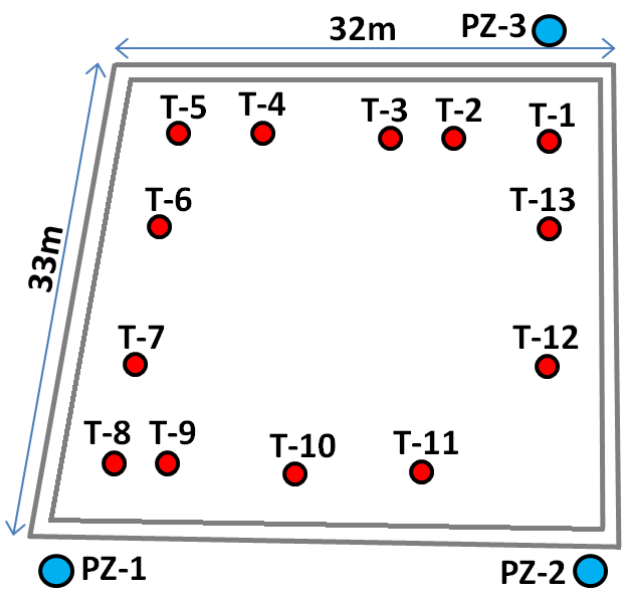

Fig. 5. Plan of the construction with the diaphragm wall as well thermal sensor and piezometer locations marked respectively as $<\mathrm{T}>$ and $<\mathrm{PZ}>$. 
The leak location details had to be urgently obtained to enable decision on further proceeding. First, a series of geophysical surveys were made from the surface. They provided no information of leak locations. The water pumping out inside the zone of excavation had lowered the water levels in all three piezometers marked in Figure 5 which were located outside of shoring. The water level in PZ-3 piezometer had lowered almost twice as much as in the other two piezometers. This confirmed the leak and indicated the strongest water inflow from the PZ-3 piezometer area but provided no precise information on the number and location of leaks. This was a typical situation. In most cases the above described actions provide no exact information on the leak location [4].

\subsection{Thermal leak detection}

Lack of positive results from the mentioned above methods made the investor seek for more effective solutions. Investigations by the thermal leak detection method were commissioned, combined with new geological surveys. The boreholes' spacing and distances from the walls were designed for the investigated case with consideration of the thermal method requirements to achieve the intended spatial accuracy of leak detection. Their arrangement is shown in Figure 5.

The grid of boreholes was denser in the new geological investigation than in the previous one, and their profiles were deeper to reach the tertiary clay layers. A selected resulting geological cross-section is shown in Fig. 2B. Differences in soil layers shapes between Figures $2 \mathrm{~A}$ and $2 \mathrm{~B}$ are visible.

Thermal investigations were carried out by NeoStrain company in partnership with the Cracow University of Technology. The diagraph wall was constructed enough time ago that there was no more hydration heat of concrete. Therefore, the active investigation method was used. Thermal investigations were carried out to the depth of $43 \mathrm{~m}$. The MCable sensors were installed vertically along the shoring walls (Figure 5). MCable sensor is multi-point thermal measuring cable integrated with the heaters. They allow the use of the active method in a linear manner along their entire length. The investigation bases on heating, over the entire length of each MCable sensor, for the same power and for a specified period of time. In the next step, the heating is turned off and the sensor is cooled. The temperature measurement curve obtained from this procedure consists of a temperature rising part and a temperature falling part (heating and cooling, respectively).

All measurement results were normalized for the whole investigation performed as a function of heating power, duration of measurement, and the maximum and minimum temperatures recorded. The normalization produced values of the Thermal-LeakageParameter (TLP) parameter in the range from 0 to 1 . The 1 means an intense flow, and the value of 0 means no flow. Limits values of scale ranges were determined by grouping similar curves in relation to their temperature increasing and their shape. The values scale and corresponding colour scale of the TLP parameter between these limits values are shown in Figure 6.

Figure 7 shows the investigation results in two vertical profiles marked as T-1 and T-2. They were superimposed on the geological cross-section in the locations of these measurement profiles. Also, the diaphragm wall bottom edge level is shown in the figure. The correlation can be seen between the locations of more intense flows (darker shades of blue) on the measurement profiles with the location of the permeable layers in the substrate. The most important result is the location of the strongest flows in the measurement profiles marked with the darkest blue colour. There is a small leakage in the diaphragm wall in investigation profile T-1. A much larger two zones of water inflow are indicated by the measurements in the T-2 profile. The lower one signifies an intense flow under the diaphragm wall bottom edge and the upper one represents a leak in the diaphragm wall. 


\begin{tabular}{|l|llr|}
\hline & 1,00 & do & 0,69 \\
\hline & 0,68 & do & 0,62 \\
\hline & 0,61 & do & 0,54 \\
\hline & 0,53 & do & 0,46 \\
\hline & 0,45 & do & 0,38 \\
\hline & 0,37 & do & 0,31 \\
\hline & 0,30 do & 0,11 \\
\hline & 0,00 & do & 0,11 \\
\hline
\end{tabular}

Fig. 6. Scale of values and corresponding colour scale of TLP (Thermal-Leakage-Parameter) parameter. Extreme values: 1 intense flow, 0 no flow.

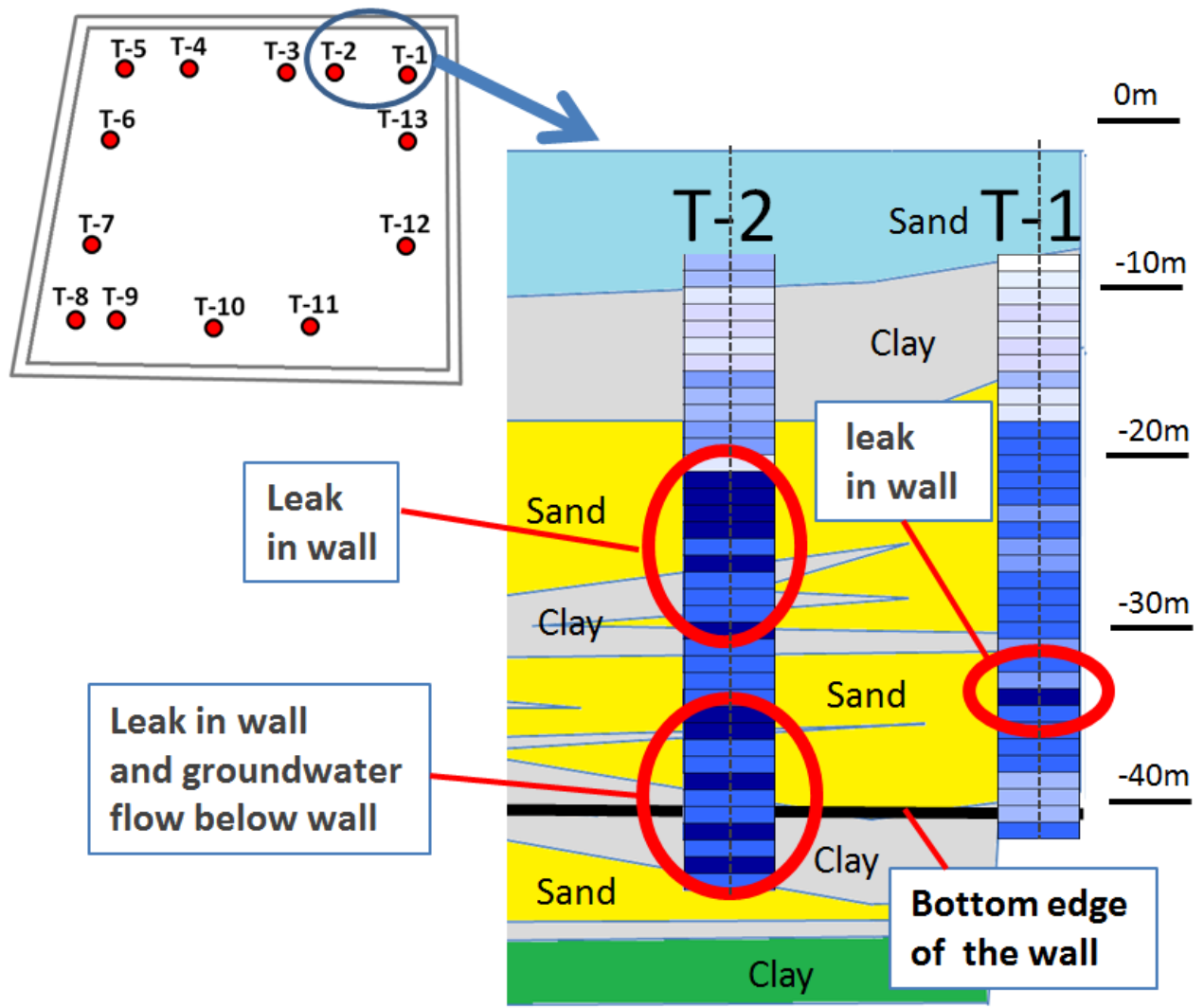

Fig. 7. Measurements results in TLP colour scale in two the selected MCables sensors over the geological cross-section. Each color bar on the profiles indicates the investigation result for separate measuring points with a spatial resolution of $1 \mathrm{~m}$.

The same way as profiles T-1 and T-2, the remaining measurement profiles were also analysed, and accurate details were obtained of leaks in the diaphragm wall and under its lower edge for the entire shoring. The summary results for the entire diaphragm wall are shown in Figure 8. 


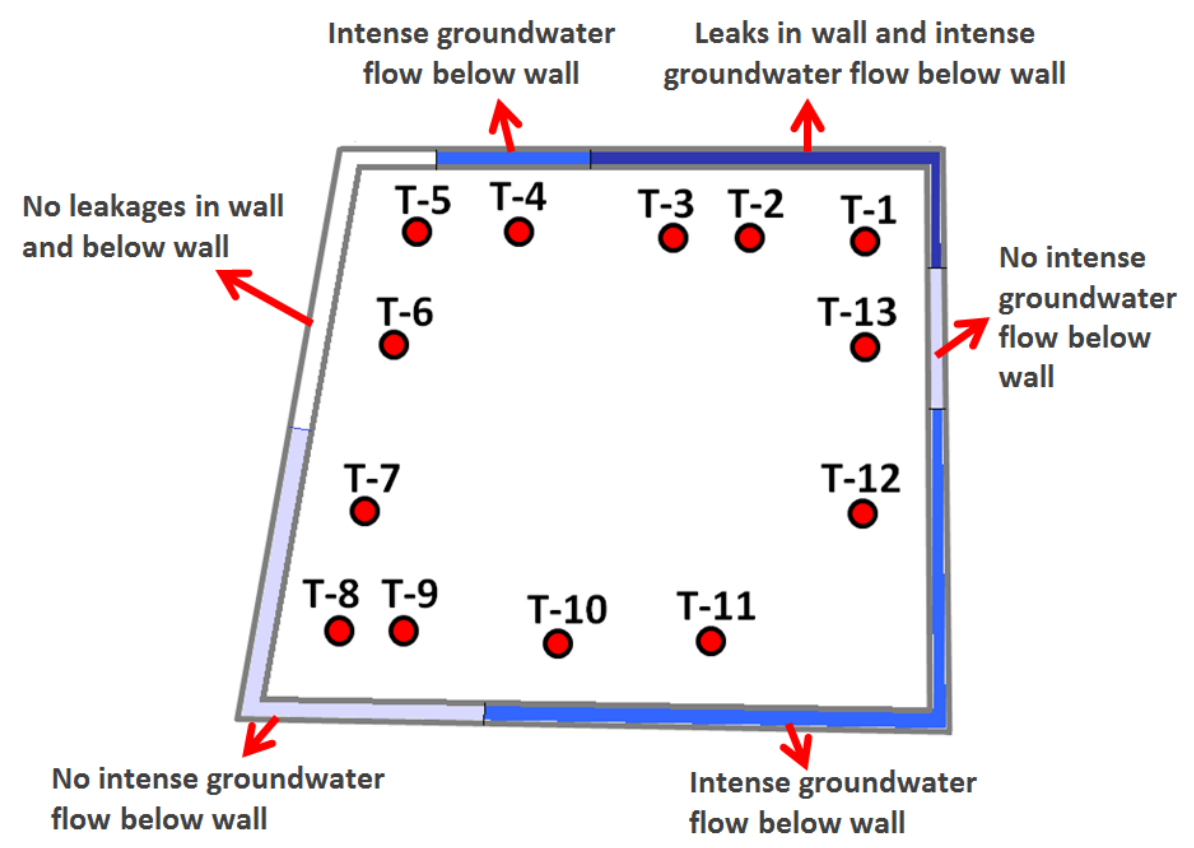

Fig. 8. Plan with summary of the thermal investigation of leakages.

\section{Conclusions}

The case presented in the paper confirms an effectiveness of the thermal method in the detection of leaks of deep excavation shorings. Vertical resolution of the thermal method is $1 \mathrm{~m}$. Its horizontal resolution depends mainly on distance between the sensors. In the described application horizontal resolution was $6 \mathrm{~m}$. If it is necessary after first detection of zone of the leakage, additional thermal sensors can be installed in this zone. In this case a spatial resolution of the method can equals up to $1 \mathrm{~m}$.

Presented real case of leak detection referred to a complicated problem. The leaks were many and occurred in the diaphragm wall as well as and under its lower edge. The depth of their occurrence reached over forty meters. The substrate's geology was highly heterogeneous. The method has produced accurate details of the leaks' locations and intensity. Such information is crucial for taking effective remedial actions and minimizing their costs. With accurate leak location details a targeted measure can be taken, such as precise injection only at the leak point. A solution to the leakage problem is essential for the fast investigation and safe resumption of construction works. In turn, failure to recognize a leakage problem may lead not only to suspension of the construction works and a significant increase in their costs due to imprecise or even wrong decisions. Leakage in an excavation shoring while it is sunk poses a threat to safety of the shoring and of neighbouring structures.

The research and results presented in this paper have been accomplished by NeoStrain Sp. z o.o. as part of "Trenchless spatial system for monitoring and detecting leakages, erosion and displacement" project co-financed by the EU's SG OP programme. 


\section{References}

1. P. Popielski, Oddziaływanie głębokich posadowień na otoczenie w środowisku zurbanizowanym, (Politechnika Warszawska Prace, Naukowe Inżynieria Środowiska, 2012) [in Polish]

2. D. Słowikowski, Geoinżynieria - drogi mosty tunele, 4, pp. 60-64 (2013) [in Polish]

3. B. Kłosiński, Geoinżynieria - drogi mosty tunele, 46, pp. 38-44 (2014) [in Polish]

4. K. Radzicki, P. Popielski, J. Dornstädter, Przegląd Geologiczny, 65(4), pp. 234-242 (2017) [in Polish]

5. K. Radzicki, Gospodarka Wodna, 6, pp. 168-174 (2017) [in Polish] 